\title{
Experience in Preservation of the Water Steam Cycle in CCPP (Combined Cycle Power Plants) with ODA (Octadecylamine)
}

\author{
Ronny Wagner and Erwin Czempik \\ $R \& D$ Department, REICON Wärmetechnik und Wasserchemie Leipzig GmbH, Leipzig 04103, Germany
}

Received: September 23, 2015 / Accepted: November 20, 2015 / Published: January 31, 2016.

\begin{abstract}
Based on the changes in the European energy market and EU goals for $\mathrm{CO}_{2}$ reduction, the fossil fired power plants, especially the high effective combined cycle power plants, are faced with new challenges. Flexible load requirements associated with frequent shutdowns especially in plants with peak load area are the results. In addition, large reserve capacities have to be retained for short-terms needs which can be quickly start operation. For this reason, preservation procedures play an increasingly important role. They should provide a good protective effect with the most simple handling and flexible management system. The preservation using FFA (film forming amines), for example, octadecylamine become more and more attraction. With the lecture, a first insight into the preservation process using octadecylamine will be given to the operators of boiler and turbine plants. Especially in the view of the further increase in supply of renewable energy and related flexibility requirements in the existing power plants, an efficient and sustainable preservation technology will be presented.
\end{abstract}

Key words: Preservation, layup, ODA, film forming amine, corrosion.

\section{Basic Requirements}

Based on the feed-in priority of electricity from renewable energy sources, fossil fueled power plants have to deal with sinking electricity prices on the one hand and rising fuel costs on the other. Even the economic operation of highly efficient combined cycle power plants is more difficult. The results are frequent starts and stops and shutdowns with unknown duration. Even coal-fired power plants must cope with flexible load requirements and longer run-times in low and part load operation. In contrast, higher reserve capacities, which are often needed quickly, must be made available.

For these reasons, preservation procedures have become more and more important. Because of different methods, the operator must decide to what

Corresponding author: Ronny Wagner, Dipl.-Wirtsch.-Ing., managing director, research fields: water chemistry, film forming amines. extent and with which technology the system should be protected during downtime. Not only have the costs of the preservation had to be taken into account. The method should also provide good protection with simple handling and it should be adjustable to flexible conditions.

\section{Preservation with ODA (Octadecylamine)}

\subsection{History and Research Work}

The use of ODA for the preservation of power plant systems has a long tradition. As early as the 1970s, several publications and patents described the effect and method of preservation with ODA [1-3].

Starting in the early 1980 's, ODA was chosen as possible preservation method for the secondary circuit of nuclear power plants. To get a better understanding, an international research project was launched with East German and Russian institutes like IfE (Institute for Energetics), ZfI (Central Institute for Isotope 
Research) and VNIIAM (All-Russian Research and Design Institute of Atomic and Energy Engineering) as well as steam generator and turbine manufacturers.

At that time, the active substance was used in its pure form. As ODA is a water-insoluble solid, the use of the pure substance makes high technical demands on the dosing stations. The active substance has to be melted on site at the facilities and kept in the liquid state for dosing. This causes serious problems.

Only by using the stable and water-soluble emulsion developed by REICON, a former part of IfE, could these problems be overcome.

In Russia, preservation with pure ODA is still carried out at nuclear facilities (e.g., Kola) and conventional power plants to this day $[4,5]$.

Nowadays, the preservation with ODA becomes more attention. New studies were carried out to give answers to actual questions from power plant operators regarding the influence of FFA (film forming amines), dosing to online analytical equipment [6] and the decomposition products under high temperature applications [7].

\subsection{Properties of ODA}

ODA is a long-chain, aliphatic amine with the chemical formula $\mathrm{C}_{18} \mathrm{H}_{37} \mathrm{NH}_{2}$. Due to its volatility and a distribution coefficient, which is similar to ammonia, a good distribution in the water and steam cycle is ensured. The active substance has the specific characteristics shown in Table 1.

Apart from the active substance, the emulsion developed by REICON (trade name ODACON ${ }^{\circledR}$ ) contains no further additives such as emulsifiers, short-chain amines or polyamines. It is a pure and stable aqueous emulsion and has a good biodegradability. The emulsion is a non-hazardous substance.

Furthermore, it is guaranteed that, the ingredients are within limits prescribed in Table 2.

The methods and results described in the following refer to the use of the ODA emulsion.
Table 1 Composition of ODA.

\begin{tabular}{ll}
\hline Primary amine & $>99 \%$ \\
Secondary amine & $<1 \%$ \\
Water content & $0.1 \%$ \\
Chain length $>\mathrm{C} 15$ & $98.5 \%$ \\
Molar weight & $261 \mathrm{~g} / \mathrm{mol}$ \\
Water solubility at $20^{\circ} \mathrm{C}$ & $1.1 \mathrm{mg} / \mathrm{L}$ \\
\hline
\end{tabular}

Table 2 Chemical purity of the emulsion.

\begin{tabular}{ll}
\hline Chloride & $<2 \mathrm{mg} / \mathrm{kg}$ \\
Sulphate & $<2 \mathrm{mg} / \mathrm{kg}$ \\
Silicate & $<0.5 \mathrm{mg} / \mathrm{kg}$ \\
Acetate & $<1 \mathrm{mg} / \mathrm{kg}$ \\
Sodium & $<1 \mathrm{mg} / \mathrm{kg}$ \\
\hline
\end{tabular}

\subsection{The Effects of ODA during Preservation}

\subsubsection{Oxygen Corrosion}

To ensure safe protection during shutdown, it is crucial that, direct contact of the material surface with humidity, oxygen or corrosive substances be prevented. To this effect, the formation of a diffusion-resistant, closed protective layer on all system parts is required. The protective layer formed during normal operation is not sufficient and is usually damaged during the starting and shutdown process. ODA, on the other hand, forms a stable, adhesive, non-wettable protective layer on a molecular level on all metallic and oxidic surfaces.

Depending on the temperature and concentration, an adsorption-desorption equilibrium forms in the water-steam cycle. First, a "physo-sorption" takes place through van-der-Waal forces. At a temperature over $100^{\circ} \mathrm{C}$, the amino group chemically bonds to the metal (ion bonding). This strong connection called "chemi-sorption" is extremely durable and leads to a long term preservation effect [8].

At sufficiently high concentration and sinking temperature (e.g., in the shutdown process), the adsorption density increases at the metal surface. The molecules align themselves with their non-polar group perpendicular to the surface. A closed, hydrophobic surface forms on components exposed to both water, as well as steam (Fig. 1). Thus, any hazardous 


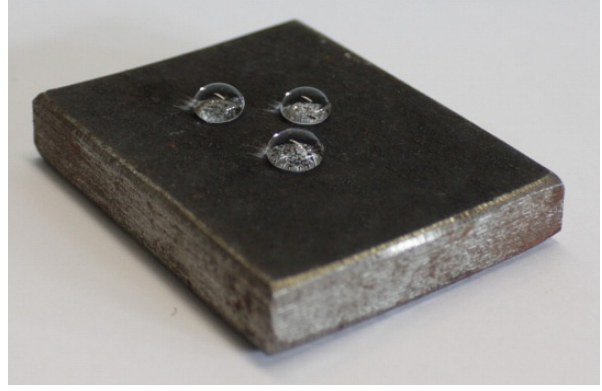

Fig. 1 Hydrophobic surfaces after preservation.

sub-stances dissolved in water such as oxygen, carbon dioxide, etc., are unable to reach the component surface to initiate corrosion.

\subsubsection{Local Corrosion}

It has been shown that, when an ODA molecule adsorbs onto the surface, deposited anions such as chlorides and sulfates are displaced and dissolved (Fig. 2). Thus, these can no longer cause corrosion, neither during operation, nor during shutdown. This applies also to construction-based structural cracks and microcracks where the anion concentration is substantially higher. Tests have shown that, preservation at a temperature of $150{ }^{\circ} \mathrm{C}$ for $24 \mathrm{~h}$ removes more than $60 \%$ of chlorides. In practice, it means that, there is significantly less danger of local corrosion and chloride-induced stress corrosion cracking.

The formation of solid deposits in the steam generator is facilitated by the introduction of impurities, mainly iron particles, from the water-steam cycle. These originate from flow-accelerated corrosion in the cycle. Frequent starting and shutdown, as well as occasional short operating cycles during which time stable water chemical parameters are difficult to achieve promote these processes.

Due to its distribution coefficient, ODA enfolds its protective effect throughout the water-steam cycle. This process is supported by the surface-activity of the substance and leads to an even coverage of all surfaces and the alkalization of water droplets. An alkaline boundary layer flow forms on the surface, which improves the formation of protective layers.

In addition, the diameter of the steam bubbles and

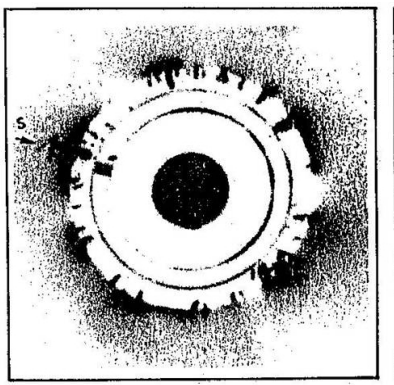

(a)

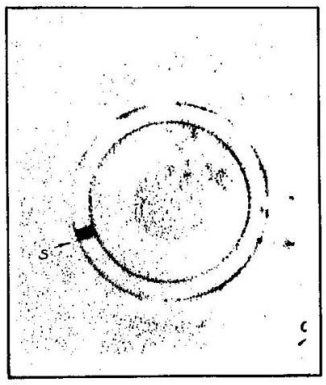

(b)
Fig. 2 Autoradiography of a strained, austenitic ring-shaped sample: (a) without ODA, (b) with ODA (degree of blackening $=$ measure of the chloride accumulation on the surface).

droplets is strongly decreased due to the reduction of the surface tension of the water (Fig. 3). These smaller droplets are diffused faster after impact on a solid surface, thus reducing the attack on the surface and material abrasion (Fig. 4) [9].

This, and the near-surface alkalization, reduces the erosive abrasion leading to a substantial decrease in the iron transport through the water steam cycle. Practical experience has shown a tenfold reduction of the iron content after preservation with ODA and re-starting the plant.

The transition from a film condensation to a droplet condensation is achieved in the turbine by the reduced water droplets. This reduces the thermodynamic losses as well as drag and braking losses. Depending on the ODA concentration, the efficiency can be increased by up to $2 \%$.

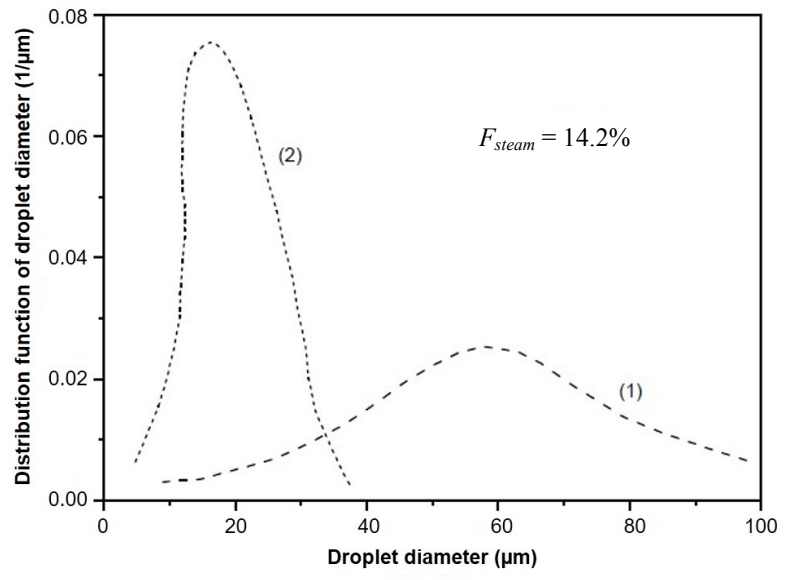

Fig. 3 Reaction distribution of the droplet size, curve (1) without ODA and curve (2) with ODA. 


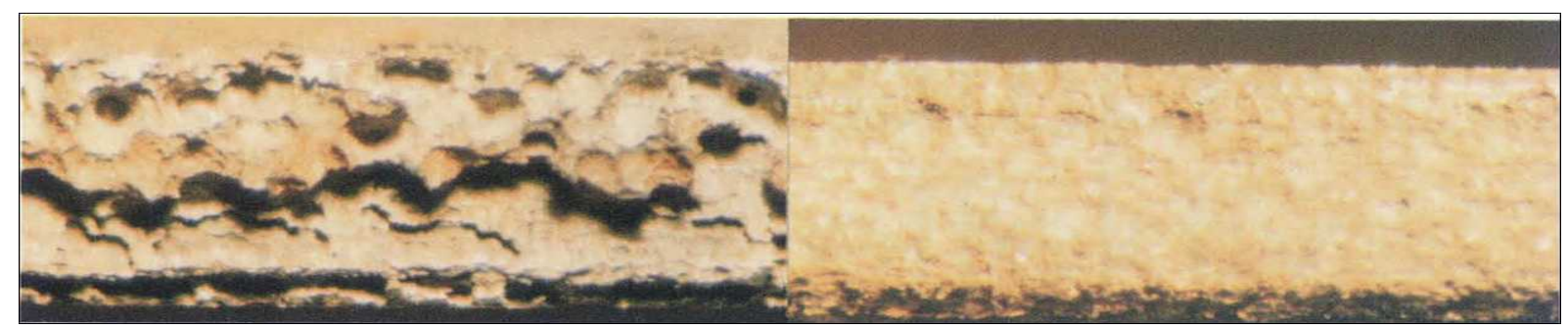

(a)

(b)

Fig. 4 Stereomicroscopic view (magnification 1:12) of the leading edge of samples of ST38, having been exposed to the water regime: (a) without ODA and (b) with ODA.

\section{Preservation Methods with ODA}

Several methods of preservation with ODA can be used, depending on the facility characteristic and operating method. No further measures are required, irrespective of the chosen method. The systems can be kept filled or be drained and can be re-started at any time, even with the remaining preservation solution.

\subsection{Preservation in Downtime}

This type of preservation is suited especially for systems which have already been shut down, or those with several boilers delivering steam to a main steam manifold.

The drained systems are filled with feed water at a temperature of about $100{ }^{\circ} \mathrm{C}$. During filling, the emulsion is dosed to the intake line of the feed water pump. If the boiler is completely filled and the ODA concentration in the boiler water is sufficient, the boiler water can be circulated externally or simply be left standing without agitation. When the system is cooling down, the adsorption processes described above come into play and the ODA protective layer is formed. Once the temperature reaches $40{ }^{\circ} \mathrm{C}$, the boiler can be emptied if required. The released boiler water requires no special treatment.

This preservation type only protects those components that are exposed to water, while the turbines and condensate system remain untreated.

\subsection{Water-Steam Cycle Preservation}

If the boiler facilities are started or shut down frequently and out of schedule, or if the systems operate only for a short time, a separate preservation can be realized only with difficulty. In this case, a small amount of ODA can be added continuously, while the facility is in operation. The active substance has no negative impact on the normal water chemical operation method. On the contrary, due to the reduced surface tension, the droplet spectrum formed in the saturated steam is reduced, while the droplet surface is alkalized at the same time. This results in drastically reduced erosive corrosion [10].

Due to the continuous presence of free ODA molecules in the water-steam cycle, an adsorption-desorption equilibrium is reached. The facility is thus immediately protected from corrosion when shut down. Furthermore, the facility can be re-started at any time without additional measures. In this method, dosing of ODA is best done through the feed water on the intake side of the feed water pump.

\subsection{Preservation in the Shutdown Process}

Preservation in the shutdown process presents the best method for preserving a complete power plant unit. The emulsion is added continuously, while the plant is still running. This is done ca. 3-10 days before the planned shutdown. The time period depends on the size of the facility, as well as the steam generating capacity and the dosing quantity. Initially, the dosing quantity is kept small and then the ODA concentration required for preservation is slowly increased. This ensures that, any mobilization effects of oxide deposits as well as those of oils and fats are controlled. Due to its volatility, the active substance is distributed 
throughout the water-steam cycle. This not only protects the boiler, but also the steam pipes, the turbine and the condensate system. Once the desired concentration necessary for preservation is reached, dosing is discontinued and the facility can be shut down.

\section{Preservation of an 800 MW Combined Cycle Power Plant in Germany}

In the past, preservation with ODA was carried out on numerous nuclear and conventional power plants. In the following, the preservation process of an $800 \mathrm{MW}$ combined cycle power plant is described.

\subsection{Facility Description}

The Statkraft Markets GmbH operates two CCPP (combined cycle power plants) at the Chemiepark Knapsack in Hürth near Cologne. CCPP Knapsack 1 has a total capacity of 800 megawatts and was commissioned in 2008. The second unit CCPP Knapsack 2 has 430 megawatts and was put into operation in 2013. Because of low electricity rates and high prices on gas at the same time, both units have only few operating hours. On the other hand, both units have to be on short call to guarantee the uninterrupted service to the chemical process industry in the area.

The CCPP Knapsack 1 consists of two SIEMENS gas turbines each 267 megawatts, two HRSG (heat recovery steam generators) with a total steam capacity of 700 ton per hours and a Siemens steam turbine with 270 megawatts. The HRSG's have a three pressure design with separate drums for each pressure stage. The operating parameters are given in Table 3. The CCPP is not equipped with a CPP (condensate polishing plant).

\subsection{Preservation Method}

To protect the boilers against standstill corrosion, Statkraft had already developed a preservation method. The boilers remain filled and get a nitrogen blanketing.
Table 3 Operating parameters at CCPP Hürth.

\begin{tabular}{llll}
\hline & Pressure & Temperature & Steam capacity \\
\hline High pressure & $114 \mathrm{bar}$ & $555^{\circ} \mathrm{C}$ & $500 \mathrm{t} / \mathrm{h}$ \\
Intermediate & $28 \mathrm{bar}$ & $545^{\circ} \mathrm{C}$ & $117 \mathrm{t} / \mathrm{h}$ \\
pressure & $4.2 \mathrm{bar}$ & $230^{\circ} \mathrm{C}$ & $72 \mathrm{t} / \mathrm{h}$ \\
\hline
\end{tabular}

The steam turbine was dried out and nitrogen was also injected. The condenser was emptied.

In January 2015, they decided to use the film forming amine ODA as additional protective method because of longer standstill periods.

Due to the short running times and the daily start stop operation, the decision was made to inject ODA continuously during operation. Anyway, the preservation had still been done in several steps to build up the protective layer in all areas of the water steam cycle.

The injection point for ODA was assembled in the main condensate line and equipped with a high pressure metering pump, and an injection lance referred to recommendations of REICON.

During the whole preservation process, a supervision program regarding the $\mathrm{pH}$-value, the cation conductivity and the degassed conductivity were done by online analytic equipment. In addition, the ODA concentration in condensate was periodically monitored.

\subsection{Results of the Supervision Program}

At the first day of first preservation period, a strong increase of the cation and degassed conductivity levels were detected due to the high ODA concentration in the cycle $(>1 \mathrm{ppm})$. This leads to an intensive mobilizing of deposits and therefore a cleaning of the surfaces.

On days 2 and 3, the ODA concentration was kept on lower levels (max. $0.7 \mathrm{ppm}$ ), but all the same the action levels 2 and 3 of VGB standard VGB-S-010-T-00 were exceeded [11].

During the second preservation period, only a gentle increase of the conductivity levels were detected, and the action level 2 of the VGB standard 

Plants) with ODA (Octadecylamine)

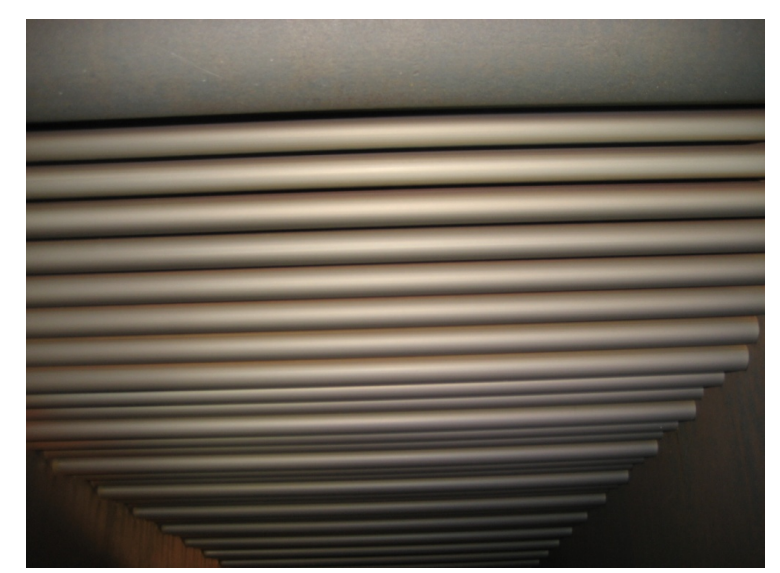

Fig. 5 Hydrophobic surfaces after preservation.

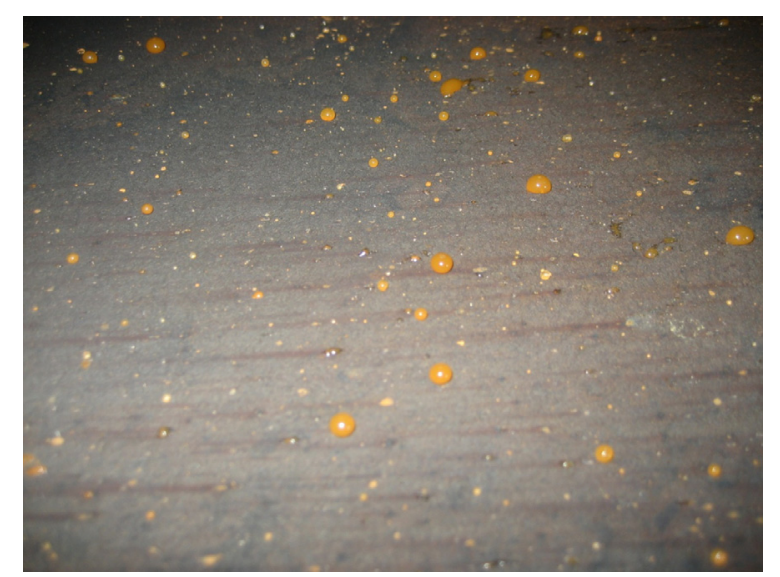

Fig. 6 Hydrophobic condenser surfaces.

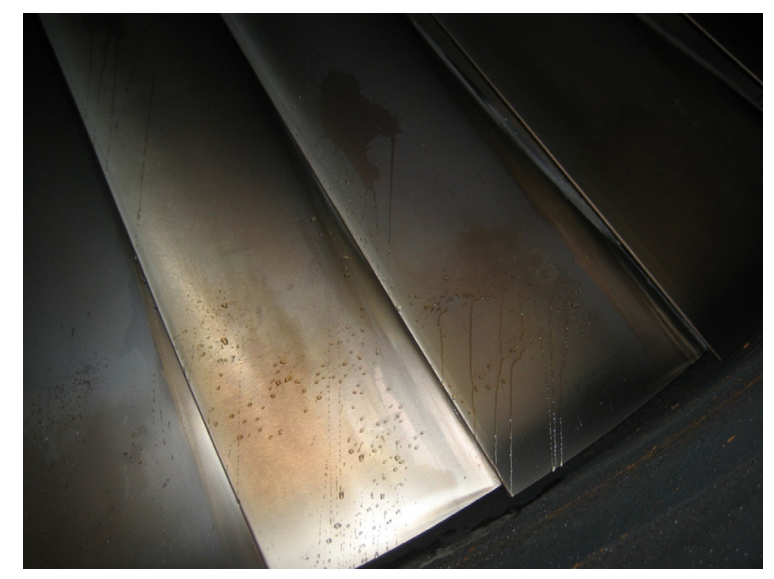

Fig. 7 Last turbine stage.

was not reached even though the injection setting was the same as at day 3 of first preservation period.

The slower and gentle increase of conductivity levels during the second preservation period shows a good surface protection through the formation of a corrosion resistent, amino-containing protection layer and an advanced cleaning of the surfaces in the water steam cycle from impurities (chloride, sulfate and organics). Also the catalytic effect of the oxidic surface was reduced, and thereby the transformation of ODA to Di-ODA and Tri-ODA under the release of ammonia.

The $\mathrm{pH}$-value remains stable during all preservation periods in spite of the strong increase of the conductivity. This shows that, no harmful organic acids were formed during the cleaning and transformation processes.

\subsection{Benefits of the Preservation with ODA}

After two periods of ODA preservation, already a lot of additional benefits were achieved. The total commissioning time is reduced from about $8 \mathrm{~h}$ to $4 \mathrm{~h}$, because the time for reaching the standard conductivity levels in steam during commissioning is decreased from $6 \mathrm{~h}$ down to $2 \mathrm{~h}$. This improves the flexibility of the power plant and enabled Statkraft to operate the plant on short call.

The visual inspection of the condenser shows the formation of a hydrophobic protection layer for the most part and the last stages of the turbine are cleaner then at former inspections (Figs. 5-7).

In all drums, a closed magnetite layer were found and only small amounts of loose oxide sludge had to be removed.

\section{Summary}

In line with providing reserve capacity to stabilize the energy grid, it will become necessary to keep power plant facilities in a state of preservation over long terms. Preservation with ODA offers the facility operator an interesting alternative to conventional preservation methods. Because the water steam cycle has not to be drained after preservation the power plant can be re-started quickly.

Due to the flexibility of the method, as well as the excellent corrosion protection during downtimes, preservation applications extend from short 
downtimes right up to long shutdowns. Using one example of many, after 8 years of downtime, a plant was brought back into operation within the shortest period of time.

\section{References}

[1] Langner, A. 1973. Verfahren zum Innenkonservieren von Dampf- und Heißwassererzeugungssystemen (Procedure for Preservation of Steam and Hot Water Generating Systems). Patent of GDR Nr. 104 107, filed May 08, 1973, and issued February 20, 1974.

[2] Langner, A., and Czempik, E. 1979. "Stand der Anwendung von Octadecylamin in den Anlagen der Wärmeerzeugung und-Versorgung (Status of Application of Octadecylamine in Heat Generation and Transportation Systems)." Vortrag auf der Fachtagung der Kraftwerkschemie (Presented at the Power Plant Chemistry Symposium), Gera, Germany.

[3] Czempik, E., Schindler, K., Filippov, G. A., and Saltanow G. A. 1978. "Einsatz Grenzflächenaktiver Stoffe in Sattdampfturbinen (Use of Surface Active Substances in Wet Steam Turbines)." Energietechnik 28 (11): 443.

[4] Kukushkin, A. N., Czempik, E., Kolomtsev, Y. V., Omelchuk, V. V., and Barmin, L. F. 2010. "Secondary Side Water Chemistry Experience with Ocdacylamine and Hydrazin Treatment at VVER Plants." Presented at the Nuclear Plant Chemistry Conference, Quebeck, Canada.

[5] Avdeev, A. A., Kukushkin, A. N., Repin, D. A., Omelchuk, V. V., Barmin, L. F., Yurmanov, V. A., and Czempik, E. 2010. "The Impact of ODA Microadditions into the Secondary System on Corrosion Rate Reduction in VVER Steam Generators." In Proceedings of the Nuclear Plant Chemistry Conference Quebeck, 296.

[6] Lendi, M., and Wuhrmann, P. 2012. "Impact of Film Forming Amines on Reliability of Online Analytical Instruments." PPChem. 14 (9): 560-7.

[7] Cao, S., Hu, J., Xie, J., Liang, Q., and Yin, L. 2013. "Research on the Film-Forming Characteristics of Octadecylamineat High Temperatures." Anti Corrosion Methods and Materials 60 (1): 14.

[8] Bäßler, R. 1997. "Beitrag zur Charakterisierung der Inhibierenden Wirkung von Octadecylamin auf die Korrosion des Stahles 1.5541 bis $250{ }^{\circ} \mathrm{C}$ (Inhibiting Effect of Octadecylamine on Pitting Corrosion Behaviour of Stainless Steel Type 1.4541 up to $250{ }^{\circ} \mathrm{C}$ ).” Doctoral thesis, TU Dresden.

[9] Leyzerovich, A. 2008. Steam Turbines for Modern Fossil-Fuel Power Plants. Lilburn, GA: The Fairmont Press, 344.

[10] Czempik, E. 1980. "Komplexe Untersuchungen des Einflusses des Oberflächenaktiven Stoffes Octadecylamin auf die Energetischen und Strukturellen Charakteristiken von Naßdampfströmungen in Turbinen und das Verhalten der Hauptausrüstungen von Wasserdampfkreisläufen. (Complex Research of the Influence of Surface Active Substance Octadecylamine to the Energetic and Structural Characteristics of Wet Steam Streams in Turbines and the Behaviour of Main Parts of the Water Steam System." Doctoral thesis, Energetisches Institut Moskau.

[11] VGB-Standard. 2012. "Feed Water, Boiler Water and Steam Quality for Power Plants/Industrial Plants." VGB-S-010-T-00, 2011-12. 